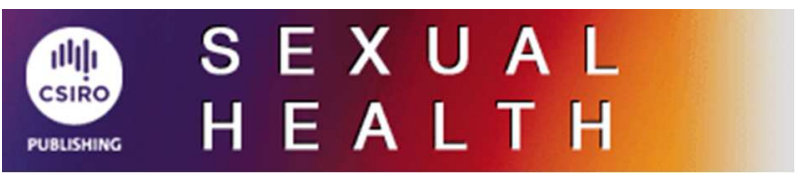

\title{
A prospective cohort study of childhood behaviour problems and adolescent sexual risk-taking: gender matters
}

\begin{tabular}{|c|c|}
\hline Journal: & Sexual Health \\
\hline Manuscript ID & SH16240.R1 \\
\hline Manuscript Type: & Research Paper \\
\hline Date Submitted by the Author: & $n / a$ \\
\hline Complete List of Authors: & $\begin{array}{l}\text { Skinner, S.; The University of Sydney, Discipline of Paediatrics and Child } \\
\text { Health } \\
\text { Marino, Jennifer; University of Melbourne, Obstetrics and Gynaecology; } \\
\text { Royal Women's Hospital, Obstetrics and Gynaecology } \\
\text { Rosenthal, Susan; Columbia University, Pediatrics; New York Presbyterian } \\
\text { Morgan Stanley Children's Hospital } \\
\text { Cannon, Jeffrey; Telethon Kids Institute } \\
\text { Doherty, Dorota; Women and Infants Research Foundation, Biostatistics } \\
\text { and Research Design Unit; University of Western Australia School of } \\
\text { Women's and Infants' Health } \\
\text { Hickey, Martha; University of Melbourne, Obstetrics and Gynaecology; } \\
\text { Royal Women's Hospital, Obstetrics and Gynaecology }\end{array}$ \\
\hline Keyword: & Youth, Sexual behaviours, Behaviour \\
\hline
\end{tabular}

\section{SCHOLARONE ${ }^{\text {m }}$}

Manuscripts 


\section{Full Title: A prospective cohort study of childhood behaviour problems and adolescent} sexual risk-taking: gender matters

\section{Short title: Childhood behaviour and adolescent risk-taking}

Prof. S. Rachel Skinner ${ }^{1}$, MBBS, PhD, Dr. Jennifer Marino ${ }^{2}, \mathrm{PhD}$, Prof. Susan L. Rosenthal ${ }^{3}$, PhD, Mr. Jeffrey Cannon ${ }^{4}$, BSc, BBus, PhC

joint senior authors Prof. Dorota A. Doherty ${ }^{5,6}, \mathrm{PhD}$ and Prof. Martha Hickey ${ }^{2}, \mathrm{MD}$

Affiliations: ${ }^{1}$ Discipline of Paediatrics and Child Health, The University of Sydney, Sydney, Australia; ${ }^{2}$ Department of Obstetrics and Gynaecology, University of Melbourne, Melbourne, Australia and the Royal Women's Hospital Melbourne, Australia; ${ }^{3}$ Columbia University College of Physicians and Surgeons and New York Presbyterian Morgan Stanley Children's Hospital, New York, United States; ${ }^{4}$ Telethon Kids Institute, The University of Western Australia, Perth, Australia; ${ }^{5}$ Biostatistics and Research Design Unit, Women and Infants Research Foundation, Perth, Australia; 'School of Women's and Infants' Health, The University of Western Australia, Perth, Australia

Address correspondence to: Professor Rachel Skinner, Discipline of Paediatrics and Child Health, University of Sydney, Children's Hospital at Westmead, Locked Bag 4001, Westmead, NSW 2054; email: rachel.skinner@sydney.edu.au ; telephone: +61 298453377 


\section{ABSTRACT}

Purpose: Externalising (delinquent, aggressive) and internalising (anxious/depressed, withdrawn) behaviour problems are prevalent in childhood. Few studies have prospectively measured relationships between childhood behaviour problems and adolescent health risk behaviour, a major predictor of morbidity and mortality. We sought to determine relationships, by gender, between childhood behaviour problems and more general adolescent health risk-taking: risky sexual behaviours, and substance use.

Methods: In a population-based birth cohort (The Western Australian Pregnancy Cohort (Raine) Study), total, externalising and internalising behaviour problems (domain-specific $\mathrm{T} \geq 60$ ) were calculated from parent-reported Child Behavior Checklist at ages two, five, eight, ten and 14. At age 17, 1,200 (49\% male) participants reported sexual activity (age of first oral sex or sexual intercourse; two or more oral sex or sexual intercourse partners; not using condom at last sexual intercourse; unwanted sex) and substance use activity (tobacco use in previous 4 weeks; having been drunk (alcohol) in previous 6 months; ever used marijuana; ever used other non-medical drugs).

Results: For both genders, those with earlier externalising behaviour problems were more likely to be sexually active (oral sex or sexual intercourse) by age 17. Males, but not females, with childhood externalising behaviour problems were more likely to have multiple sexual partners by age 17 than those without such problems (adjusted odds ratio (aOR) 2.96, 95\% confidence interval (CI) 1.49-5.86). Females, but not males, with childhood externalising behaviour problems were more likely to have had unwanted sex (aOR 1.91, 95\%CI 1.043.53). Externalising behaviour problems were associated with substance use for both genders. No association was found between internalising behaviour problems and risky behaviour. Conclusions: Externalising behaviour problems from as early as 5 in boys and 8 in girls predict a range of risky sexual behaviour in adolescence, which has important implications for targeting interventions in adolescence. 


\section{BACKGROUND}

Adolescent health-compromising behaviours ("risky behaviours") include developmentally normal behaviours with potentially adverse consequences, particularly at younger ages (e.g. sexual behaviours and alcohol/substance use) and behaviours that may have negative consequences at any age (e.g. unprotected sex, multiple sexual partners, heavy alcohol use, regular tobacco use, and illicit drugs). There are gender differences in adolescent health-compromising behaviours, with a male preponderance of substance use (1), physical risk taking (2) and sexual risk (3). Health-compromising behaviour is responsible for the majority of adolescent and young adult morbidity and mortality worldwide (4) and evidence for effective interventions to reduce health-compromising behaviour and associated morbidity is limited (5).

Understanding the nature of adolescent health risk behaviour has implications for improving adolescent health and well-being. Importantly, problem behaviour in childhood, particularly of the externalising type, which is associated with impulsivity, breaking rules, and taking risks, has been linked to higher rates of health-compromising behaviour in adolescence, such as substance use, and earlier age of first sexual intercourse $(6,7)$. Further delineation of the relationship between childhood problem behaviour and adolescent health-compromising behaviour is warranted if we are to develop effective intervention strategies.

Childhood behaviour problems are common and include behaviour of the externalising and internalising type. Externalising behaviour is "acting-out" behaviour linked to emotional under-control and disinhibition $(8,9)$. Internalising behaviour includes "emotional problems" reflecting a tendency to turn negative experiences inward, such as depressive and anxiety symptoms $(9,10)$. Externalising problems are more common among boys, and internalising problems among girls $(11,12)$. Problem behaviour in childhood has been extensively studied due to the health and economic burden on families 
of challenging behaviour and its link to mental health disorders. Problem behaviours are central to clinical disorders: externalising to attention deficit disorder/hyperactivity disorder and conduct disorders, and internalising to anxiety and depressive disorders. Together, these disorders affect 1 in 8 Australian children and adolescents (13), while data from other countries is sparse.

Despite the likely high prevalence of childhood externalising and internalising problems, and of adolescent health-compromising behaviour, few prospective studies have followed children with behaviour problems into adolescence to examine their association. Understanding these associations may inform the targeting (including by gender) and timing of surveillance or interventions for at-risk children. These studies require large population-based cohorts followed prospectively through childhood into adolescence and young adulthood. Drawing on prospective data from the Raine Study birth cohort, we previously reported that externalising problems from early childhood predicted younger age at first sexual intercourse (FSI) in both genders_(14). Building on this finding, the aim of the current study was to determine explore how this relationship extends to adolescent sexual risk taking across a broader range of sexual behaviours, and substance abuse, and to ascertain whether associations are gender-specific.

\section{METHODS}

\section{Participants}

The Western Australian Pregnancy Cohort (Raine) Study is a prospective cohort study of 2,868 live births (1,405 female, 1,463 male) from 2,900 pregnancies followed since 1989. Cohort details are published elsewhere (15). Briefly, the cohort was recruited at 18 weeks' gestation at a tertiary maternity hospital in Western Australia. Children and their families were surveyed at ages one, two, three, five, eight, ten, 14, and 17 years. After 
baseline data collection, families were not required to have participated in previous waves to participate subsequently.

Written informed consent was obtained at enrolment and at each follow-up. Study protocols were approved by the Human Ethics Committees at King Edward Memorial Hospital and Princess Margaret Hospital for Children in Perth, Western Australia.

\section{Behavioural variables}

The Child Behavior Checklists for Ages 2/3 (CBCL/2-3) and Ages 4-18 (CBCL/418) measure child behaviour by parent report $(16,17)$. The CBCL instruments have shown good internal consistency in diagnosis of child psychopathology, are comparable with standardized diagnostic interviews in identifying children and adolescents with psychiatric morbidity (18) and have been widely used internationally in studies of behavioural development (19). The instruments measure the constructs Withdrawal, Anxiety/Depression, Social Problems, Thought Problems, Attention Problems, Delinquent Behaviour, Aggressive Behaviour, and, in the CBCL/4-18, Somatic Complaints. These constructs comprise the Total Problems (TB) score. The Internalising Behavior score comprises Withdrawal and Anxiety/Depression, plus, for the CBCL/4-18, Somatic Complaints. The Externalising Behavior score comprises Delinquent and Aggressive Behaviour. Parents completed the CBCL/2-3 at the two-year follow-up and the CBCL/418 at the five, eight, ten, and 14 year follow-ups. Raw scores were standardized by age and sex to produce $T$-scores with mean 50 and standard deviation 10 (16). Consistent with published cut-off values (16), problem behaviour was defined as $T$-score $\geq 60$ (borderline and clinically significant behaviour).

Outcome variables

Self-reported sexual behaviour and substance use data were collected at age 17 years using a confidential online questionnaire. Sexual behaviour questions were derived 
from the Australian National Survey of Secondary School Students, HIV/AIDS and Sexual Health, 2002 (20), and substance use questions from the Australian School Students' Alcohol and Drug Survey, 2002 (21). We defined "age of first sexual experience" as age (in years) of first sexual intercourse (FSI) or first oral sex (FOS), whichever occurred first. We defined participants as "sexually active" at the 17-year follow-up if they had experienced FSI or FOS (irrespective of partner gender). For those who were "sexually active", the individual risky sexual behaviours identified for analysis included 1) having had two or more oral sex (2+ OS) partners in the previous year, 2) having had two or more sexual intercourse $(2+\mathrm{SI})$ partners in the previous year, 3) not having used condoms at the most recent sexual intercourse encounter, and 4) ever having "had sex when you didn't want to" (intercourse only). These outcomes were selected because they are reliably recalled and most consistently associated with higher risk of STI or unplanned pregnancy (22-24). Individual risky substance use behaviours for analysis included 1) having smoked cigarettes in the previous four weeks (tobacco use), 2) having been drunk at any time in the previous six months (alcohol use), 3) ever having used "marijuana (mull, grass, pot)" (cannabis use), and 4) ever having used any other drug for non-medical purposes, specifically: inhalants, painkillers, amphetamines, or "party drugs (e.g. ecstasy, LSD or nitrous oxide" (illicit drug use). These variables were chosen for their association with short and longer-term adverse outcomes, including problematic substance use (25-27).

\section{Control variables}

We controlled for demographic and family characteristics at baseline (during pregnancy) including maternal age, parental educational attainment, mothers' relationship status (presence or absence of the biological father in the home), family income, and parental substance use. A priori models were constructed based on findings in our previous paper(14). 


\section{Statistical analyses}

Categorical data (sociodemographic data) were summarized with frequency distributions and univariate group comparisons by sexual activity status were conducted using chi-squared tests. Primary analyses examined the effects of clinically significant TB, externalising, and internalising problems on age at FSI and FOS using univariate and multivariable Cox regression analysis. Effects of externalising and internalising problems on age at FSI and FOS were summarized using hazard rate ratios (HR) and 95\% confidence intervals (CI). Effects of externalising and internalising problems on experience of risky sexual behaviours (either multiple partners over the course of the previous year, condom use or unwanted sex) in the subset of sexually active study participants and on reported substance use (alcohol, smoking and drug use) were analyzed by multivariable logistic regression, and summarized using odds ratios (OR) and 95\% CIs.

All analyses were implemented in gender-specific models (14). Male models were adjusted for maternal age and smoking; female models were further adjusted for any parental drug use, and father absence.

All hypothesis tests were two-sided and $\mathrm{p}$-values $<0.05$ were considered statistically significant. SPSS for Windows software (version 18, SPSS Inc., Chicago, IL) was used for data analysis.

\section{RESULTS}

Baseline sociodemographic variables and adolescent sexual activity

At the 17 year follow-up, there were 1,645 non-responders (57.8\%) and 1200 responders (42.3\%) giving a total of 2,845 from the initial cohort of 2,868 (after excluding 19 neonatal deaths, 1 childhood death and 3 cases of missing data). Data were collected from 607 female and 593 male participants aged 17 years (female median age $17.0 \mathrm{y}$, interquartile range (IQR) 16.9-17.1 y, range 16.6-18.9 y; male median age 17.0 y, IQR 
16.9-17.1y, range 16.0-18.2 y). Of these, 374 females (61.6\%) and 331 males (55.8\%) were sexually active (had experienced oral sex (OS) and/or vaginal sexual intercourse (SI)).

Sexually active female adolescents were more likely to have mothers who were younger and less educated, parents who smoked or used illicit drugs during pregnancy, and absent fathers (Table 1). Sexually active male adolescents were more likely to have had less educated mothers, parents who smoked during pregnancy, and fathers who used illicit drugs during pregnancy (Table 1).

\section{Sexual experiences}

Most sexually active participants reported both OS and SI (females $n=291,77.8 \%$, males $n=252,76.1 \%$ ), mostly in the same year of life (females $n=188,64.6 \%$, males $\mathrm{n}=149,59.1 \%$; Table 2$)$. Amongst those reporting SI, $40.0 \%(\mathrm{n}=123)$ of females and $48.5 \%$ of males $(\mathrm{N}=128)$ reported $2+$ partners in the past year. Amongst those reporting OS, $36.4 \%(\mathrm{~N}=130)$ of females and $48.2 \%(\mathrm{~N}=154)$ of males reported $2+$ partners in the past year. Amongst those reporting SI, 136 females (44.2\%) and 66 males (25.0\%) reported not using a condom at last intercourse, and 80 females (26.0\%) and 33 males $(12.5 \%)$ reported unwanted SI. The most commonly reported reasons for unwanted sex were the same for females and males, with $46.3 \%$ of females $(\mathrm{N}=37)$ and $60.6 \%$ of males $(\mathrm{N}=20)$ reporting they were "too drunk at the time" or "too high at the time", and $40.0 \%$ of females $(\mathrm{N}=32)$ and $45.5 \%$ of males $(\mathrm{N}=15)$ stating that "(their) partner thought they should".

\section{Childhood problem behaviour and adolescent sexual activity}

Table 3 presents frequency of behaviour problems (CBCL $T \geq 60$ ) by gender and sexual activity status. Both female and male adolescents who had externalising problems from age 5 onwards were more likely to be sexually active by age 17 . The association of 
TB problems and sexual activity was similar to the relationship of externalising problems and sexual activity in males but was less consistent in females. There was no association between internalising problems and sexual activity in either gender.

Adjusted relative rates of first sexual experience by childhood externalising/internalising problems are presented for males and females in Table 4. Females who had externalising problems at ages 10 and 14 reported a higher rate of FOS than those who did not, whilst females with externalising problems only at age 14 reported a higher rate of FSI. There were no differences in rate of first sexual experience by internalising problems among females. Males who had externalising problems from age 5 onwards reported a higher rate of FOS. Males who had externalising problems from age 5 onwards reported a higher rate of FSI: for males with externalising problems at the age-10 assessment the FSI rate nearly doubled.

Among females, externalising problems were not related to having $2+$ SI partners (Table 5). Males with externalising problems, evident from as young as age 5 onwards, were two to three times more likely to report having had 2+ SI partners. Females with externalising problems at age 8 but at no other age were more likely to report $2+$ OS partners. Males with externalising problems at ages 10 and 14 were more likely to have 2+ OS partners. For both females and males, externalising problems at any age were unrelated to condom use at last sexual intercourse. Female participants with externalising problems at ages 8,10 , or 14 were more likely to report unwanted sex, but this relationship did not exist for males.

There were no consistent associations between internalising problems in childhood and any specific risky sexual behaviour for males or females (Table 6).

Childhood problem behaviour and adolescent substance use 
112 males (18.9\%) and 135 females (22.2\%) had smoked cigarettes in the previous 4 weeks, 381 males (64.2\%) and 403 females (66.4\%) had been drunk in the previous six months, 200 males (34.2\%) and 200 females (33.3\%) had ever used cannabis, and 70 males (11.9\%) and 84 females (14.0\%) had ever used any other illicit drug. In females, externalising problems at age 13 increased likelihood of both cigarette and illicit drug use (Table 5). In females, there were no other consistent associations between externalising or internalising problems and other substance use (Tables 5 and 6). In males, externalising problems from age 5 predicted both cigarette and cannabis use (Table 5). There were no other consistent associations between externalising or internalising problems and other substance use (Tables 5 and 6).

\section{DISCUSSION}

A novel finding from our study was the clear gender difference in the association between early childhood externalising behaviour problems and risky sexual behaviour. In males as young as age 5 there were consistent and strong relationships between childhood externalising problems and later risky sexual behaviour in adolescence. The only exception was unwanted SI, which was more common and associated with childhood externalising problems only in girls. This may reflect the greater vulnerability of female adolescents to unwanted sex. Further, we found strong associations between childhood externalising problems and a range of risky sexual behaviours in adolescence including younger age at first sexual experience. We also found strong associations between childhood externalising problems and smoking and cannabis use in adolescence. These associations were seen in both genders, but were apparent earlier in males than females.

The key clinical significance of our findings is that externalising problems in boys from as young as 5 years old consistently predict a more extensive range of risky sexual, drug and alcohol behaviours than previously reported, including specific types of risky 
sexual behaviour. The strong male bias in the early appearance of this association builds on our earlier findings (14) and extends our understanding of gender influences. Our findings suggest that the externalising phenotype in childhood which persists into adolescence might manifest as health-compromising behaviours in males in particular, and notably, specifically as sexual behaviours. The important gender biases raise questions around the nature of the association. It is well recognized that externalising problems are more pronounced in males $(11,12)$, as are certain health risk behaviours $(2,28,29)$. Whether these represent common mechanisms (such as poorer impulse control and executive functioning and higher levels of sensation seeking) is not well understood (3, 30). Early externalising problems may also lead to disengagement from school, prosocial peer and family structures that may increase the risk for later antisocial behaviour such as substance use and early sexual activity $(31,32)$. Adolescent behaviours also reflect social and cultural influences which differ by gender and may have influenced reporting and/or practice of risky behaviours $(33,34)$. Understanding the evolution of pathological childhood problem behaviour and risk for adolescent health-compromising behaviour, and the role of gender differences, has important implications for developing effective prevention strategies. Further, we report that girls with externalising problems from as young as 8 years old are at increased risk of unwanted SI in adolescence. Our findings are consistent with previous studies addressing substance use (35-41), but this is the prospective first study to have reported the relationship between early childhood behaviours and later sexual risk-taking in addition to alcohol and substance use.

This is the first large prospective cohort study to have collected data on oral sex as well as intercourse. Problem externalising in childhood predicted younger age at FOS in both males and females, but was apparent earlier in males. This gendered pattern was replicated for other risky sexual behaviours including multiple SI and OS partners. It is 
interesting that while we identified a consistent link between externalising problems and risky sexual behaviours in adolescence, this did not extend to reported lack of condom use at last SI in either gender, despite relatively high reported condom use prevalences overall (56\% in females, $75 \%$ in males).

SI and OS prevalences were similar to those in a contemporaneous, nationally representative sample of Australian $12^{\text {th }}$-graders (20). Among sexually active adolescents in our sample, the prevalence of most 'risky' sexual behaviours was similar to those from this national sample and to those from the UK (42) and the US (43). In both genders, more adolescents reported OS than SI, suggesting that OS may be a better marker of sexual debut in adolescence. However, in most cases these sexual experiences had a close temporal link.

A major strength of our study is the design, which prospectively measured child problem behaviour in six waves, from age 2 until 14, in a large, representative birth cohort, using a well-validated, commonly used, clinically relevant instrument (CBCL). A further strength is that we report a broad spectrum of behavioural risk outcomes in two domains, sexuality and substance use. We used computer-assisted interview, which has been shown to have good reliability for teenage self-reported sexual behaviour and substance use (44). Few cohort studies have collected detailed sexual behaviour during adolescence, and some rely on unplanned pregnancy as an indicator of sexual activity $(37,40)$. By collecting data at age 17 years, recall bias was minimized. Only around half of the cohort was sexually experienced by age 17 years, which limited our power to detect associations. However, the consistency in association of externalising problems with a range of risky sexual and substance use behaviours adds strength to our findings. We plan to extend our work in the $\underline{\text { Raine cohort by examining relationships between childhood behaviour problems and }}$ 
health-related risk behaviour in other domains, such as diet/obesity, physical inactivity, and injury. This work is the subject of research grant applications currently under review.

Those who were sexually active before age 17 were likely to be a higher-risk group than average, which may affect the generalizability of all of our findings. Data on sexual abuse have not been collected in this cohort, and this may be an important confounder of the relationship between childhood problem behaviour and risk-taking. However, selfreported sexual activity under 13 years was rare (14). In studies of adults or high-risk youth, "multiple partners" may be defined as more than three or more than four partners in a year. However, in a general-risk population with median age of 17 years, having more than one partner for sexual intercourse or oral sex in a year puts the participant in the highest quartile of the sample and hence constitutes risky behaviour, consistent with other $\underline{\text { studies of general-risk Australian youth }-(45,46) \text {. Problem behaviour was based on the }}$ parent-reported CBCL, while outcomes relied on adolescent report. Our analyses have found $80 \%$ agreement of parent-adolescent dyads on CBCL and Youth Self-Report assessment of problem behaviour (manuscript under review). Another limitation of the study is that sexual activity had been ascertained only once during follow-up, at the time of this writing.

\section{CONCLUSION}

In this large, population-based prospective birth cohort study, we report that early childhood externalising behaviour predicts a range of risky adolescent sexual and other behaviours in males from as young as 5 years. Similar associations were seen in females but appeared in later childhood, except for the association with unwanted sex. These findings have implications for the targeting and timing of early interventions to prevent adolescent risky behaviour. 


\section{REFERENCES}

1. Fergusson DM, Horwood LJ, Ridder EM. Show me the child at seven. J Child Psychol Psychiatry2005 Aug;46(8):837-49.

2. Byrnes JP, Miller DC, Schafer WD. Gender differences in risk taking: A meta-analysis. Psychol Bul11999 May;125(3):367-83.

3. Dir AL, Coskunpinar A, Cyders MA. A meta-analytic review of the relationship between adolescent risky sexual behavior and impulsivity across gender, age, and race. Clin Psychol Rev2014 Nov;34(7):551-62.

4. World Health Organization. Health for the world's adolescents. A second chance in the second decade. Geneva2014.

5. Patton GC, Sawyer SM, Santelli JS, Ross DA, Afifi R, Allen NB, et al. Our future: a Lancet commission on adolescent health and wellbeing. The Lancet2016;387(10036):2423-78.

6. Skinner SR, Robinson M, Smith MA, Robbins SCC, Mattes E, Cannon J, et al. Childhood behavior problems and age at first sexual intercourse: A prospective birth cohort study. Pediatrics2015 Feb;135(2):255-63.

7. Thompson R, Tabone JK, Litrownik AJ, Briggs EC, Hussey JM, English DJ, et al. Early adolescent risk behavior outcomes of childhood externalizing behavioral trajectories. J Early Adolescence2011 Apr;31(2):234-57.

8. Olson SL, Sameroff AJ, Lansford JE, Sexton H, Davis-Kean P, Bates JE, et al.

Deconstructing the externalizing spectrum: Growth patterns of overt aggression, covert aggression, oppositional behavior, impulsivity/inattention, and emotion dysregulation between school entry and early adolescence. Development and Psychopathology2013 Aug;25(3):817-42.

9. Achenbach TM, Edelbrock CS. Classification of Child Psychopathology - Review and Analysis of Empirical Efforts. Psychol Bull1978;85(6):1275-301.

10. Liu J, Chen X, Lewis G. Childhood internalizing behaviour: analysis and implications. Journal of Psychiatric and Mental Health Nursing2011 Dec;18(10):884-94. 
11. Thijs PE, van Dijk IK, Stoof R, Notten N. Adolescent problem behaviour: The gender gap in European perspective. Eur J Criminol2015 Sep;12(5):598-615.

12. Ormel J, Oldehinkel AJ, Sijtsema J, van Oort F, Raven D, Veenstra R, et al. The TRacking Adolescents' Individual Lives Survey (TRAILS): design, current status, and selected findings. J Am Acad Child Adolesc Psychiatry2012 Oct;51(10):1020-36.

13. Lawrence D, Johnson SE, Hafekost J, Boterhoven de Haan K, Sawyer MG, Ainley J, et al. The Mental Health of Children and Adolescents: Report on the second Australian Child and Adolescent Survey of Mental Health and Wellbeing. Canberra, Australia: Department of Health; 2015.

14. Skinner SR, Robinson M, Smith MA, Robbins SC, Mattes E, Cannon J, et al. Childhood behavior problems and age at first sexual intercourse: a prospective birth cohort study. Pediatrics2015 Feb;135(2):255-63.

15. Newnham JP, Evans SF, Michael CA, Stanley FJ, Landau LI. Effects of frequent ultrasound during pregnancy: A randomised controlled trial. Lancet1993;342:887-91.

16. Achenbach TM. Manual for the Child Behavior Checklist/4-18 and 1991 Profile. Burlington: University of Vermont, Department of Psychiatry; 1991.

17. Achenbach TM, Edelbrock C, Howell CT. Empirically based assessment of the behavioural/emotional problems of 2- and 3-year-old children. Journal of Abnormal Child Psychology1987;15(4):629-50.

18. Zubrick S, Silburn S, Gurrin L, Teoh H, Shepherd C, Carlton J, et al. Western Australian Child Health Survey: education, health and competence. Perth, Western Australia: Australian Bureau of Statistics and the Telethon Institute for Child Health Research (ISBN 064217239 0)1997.

19. Bérubé RL, Achenbach TM. Bibliography of published studies using the ASEBA. Burlington, VT: University of Vermont, Research Center for Children, Youth, \& Families2007. 20. Smith A, Agius P, Mitchell A, Barrett C, Pitts M. Secondary Students and Sexual Health 2008. Melbourne: Australian Research Centre in Sex, Health \& Society, La Trobe University.2009. 
21. White V, Hayman J. Smoking behaviours of Australian secondary students in 2002.

Canberra, Australia2004.

22. Santelli JS, Brener ND, Lowry R, Bhatt A, Zabin LS. Multiple sexual partners among U.S. adolescents and young adults. Fam Plann Perspect1998 Nov-Dec;30(6):271-5.

23. Morris L, Warren CW, Aral SO. Measuring adolescent sexual behaviors and related health outcomes. Public Health Rep1993;108 Suppl 1:31-6.

24. Trent M, Clum G, Roche KM. Sexual victimization and reproductive health outcomes in urban youth. Ambul Pediatr2007 Jul-Aug;7(4):313-6.

25. DeLisi M, Angton A, Behnken MP, Kusow AM. Do adolescent drug users fare the worst? Onset type, juvenile delinquency, and criminal careers. International Journal of Offender Therapy and Comparative Criminology2015 February 1, 2015;59(2):180-95.

26. Grant BF, Dawson DA. Age at onset of alcohol use and its association with DSM-IV alcohol abuse and dependence: results from the national longitudinal alcohol epidemiologic survey. Journal of Substance Abuse1997 //;9:103-10.

27. Dierker L, He J, Kalaydjian A, Swendsen J, Degenhardt L, Glantz M, et al. The importance of timing of transitions for risk of regular smoking and nicotine dependence. ann behav med2008 2008/08/01;36(1):87-92.

28. Cotto JH, Davis E, Dowling GJ, Elcano JC, Staton AB, Weiss SRB. Gender effects on drug use, abuse, and dependence: A special analysis of results from the national survey on drug use and health. Gender Medicine2010 10//;7(5):402-13.

29. Pinkhasov RM, Wong J, Kashanian J, Lee M, Samadi DB, Pinkhasov MM, et al. Are men shortchanged on health? Perspective on health care utilization and health risk behavior in men and women in the United States. International Journal Of Clinical Practice2010;64(4):475-87.

30. Kuhn C. Emergence of sex differences in the development of substance use and abuse during adolescence. Pharmacology \& Therapeutics. [Review]. 2015 Sep;153:55-78.

31. Jager J, Yuen CX, Putnick DL, Hendricks C, Bornstein MH. Adolescent-Peer

Relationships, Separation and Detachment From Parents, and Internalizing and Externalizing Behaviors: Linkages and Interactions. J Early Adolescence2015 May;35(4):511-37. 
32. Loukas A, Cance JD, Batanova M. Trajectories of School Connectedness Across the Middle School Years: Examining the Roles of Adolescents' Internalizing and Externalizing Problems. Youth Soc2016 Jul;48(4):557-76.

33. Schroder KEE, Carey MP, Vanable PA. Methodological challenges in research on sexual risk behavior: II. Accuracy of self-reports. Ann Behav Med2003 Oct;26(2):104-23.

34. Brener ND, Kann L, McManus T, Kinchen SA, Sundberg EC, Ross JG. Reliability of the 1999 youth risk behavior survey questionnaire. J Adolesc Health2002 Oct;31(4):336-42.

35. Fischer JA, Najman JM, Williams GM, Clavarino AM. Childhood and adolescent psychopathology and subsequent tobacco smoking in young adults: findings from an Australian birth cohort. Addiction2012;107(9):1669-76.

36. Miettunen J, Murray GK, Jones PB, Mäki P, Ebeling H, Taanila A, et al. Longitudinal associations between childhood and adulthood externalizing and internalizing psychopathology and adolescent substance use. Psychological Medicine2014;44(08):1727-38.

37. Fergusson DM, Horwood LJ, Ridder EM. Conduct and attentional problems in childhood and adolescence and later substance use, abuse and dependence: Results of a 25-year longitudinal study. Drug Alcohol Depen2007 Apr;88:S14-S26.

38. Fergusson DM, John Horwood L, Ridder EM. Show me the child at seven: the consequences of conduct problems in childhood for psychosocial functioning in adulthood. J Child Psychol Psyc2005 Aug;46(8):837-49.

39. Fergusson DM, Lynskey MT. Conduct problems in childhood and psychosocial outcomes in young adulthood: A prospective study. J Emot Behav Disord1998 Spr;6(1):2-18.

40. Bardone AM, Moffitt TE, Caspi A, Dickson N, Stanton WR, Silva PA. Adult physical health outcomes of adolescent girls with conduct disorder, depression, and anxiety. J Am Acad Child Adolesc Psychiatry1998 Jun;37(6):594-601.

41. Meier MH, Hall W, Caspi A, Belsky DW, Cerdá M, Harrington HL, et al. Which adolescents develop persistent substance dependence in adulthood? Using populationrepresentative longitudinal data to inform universal risk assessment. Psychological Medicine2015;FirstView:1-13. 
42. Mercer CH, Tanton C, Prah P, Erens B, Sonnenberg P, Clifton S, et al. Changes in sexual attitudes and lifestyles in Britain through the life course and over time: findings from the National Surveys of Sexual Attitudes and Lifestyles (Natsal). The Lancet2013;382(9907):1781-94.

43. Eaton DK, Kann L, Kinchen S, Shanklin S, Ross J, Hawkins J, et al. Youth risk behavior surveillance--United States, 2007. Morbidity and mortality weekly report Surveillance summaries (Washington, DC : 2002)2008 2008 Jun;57(4):1-131.

44. Watson PD, Denny SJ, Adair V, Ameratunga SN, Clark TC, Crengle SM, et al. Adolescents' perceptions of a health survey using multimedia computer-assisted self-administered interview. Aust N Z J Public Health2001 Dec;25(6):520-4.

45. Mitchell A, Patrick K, Heywood W, Blackman P, Pitts M. 5th National Survey of Australian Secondary Students and Sexual Health 2013. Melbourne: Australian Research Centre in Sex, Health, and Society, Latrobe University; 2014.

46. Jenkinson R, Bowring A, Dietze P, Hellard M, Lim MS. Young risk takers: Alcohol, illicit drugs, and sexual practices among a sample of music festival attendees. J Sex Transm

Dis2014;2014:357239. 
Table 1. Early life characteristics and maternal demographics in pregnancy by sexual activity status of participants at the 17-year follow-up.

\begin{tabular}{|c|c|c|c|c|c|c|c|c|}
\hline & \multicolumn{4}{|c|}{ Female } & \multicolumn{4}{|c|}{ Male } \\
\hline & All & $\begin{array}{c}\text { Sexually } \\
\text { active }\end{array}$ & $\begin{array}{c}\text { Not sexually } \\
\text { active }\end{array}$ & & All & $\begin{array}{c}\text { Sexually } \\
\text { active }\end{array}$ & $\begin{array}{c}\text { Not } \\
\text { sexually } \\
\text { active }\end{array}$ & \\
\hline Characteristic & $n(\%)$ & $n(\%)$ & $n(\%)$ & $p^{\text {a }}$ & $n(\%)$ & $n(\%)$ & $n(\%)$ & $p^{\text {a }}$ \\
\hline All participants & $607(100)$ & $374(61.6)$ & $233(38.4)$ & - & $593(100)$ & $331(55.8)$ & $262(44.2)$ & - \\
\hline \multicolumn{9}{|c|}{ Maternal age at delivery } \\
\hline$<20$ years & $55(9.1)$ & $42(11.2)$ & $13(5.6)$ & $<0.001$ & $44(7.4)$ & $24(7.3)$ & $20(7.6)$ & 0.43 \\
\hline $20-24$ years & $120(19.8)$ & $94(25.1)$ & $26(11.2)$ & & $115(19.4)$ & $69(20.8)$ & $46(17.6)$ & \\
\hline $25-29$ years & $181(29.8)$ & $102(27.3)$ & 79 (33.9) & & $192(32.3)$ & $111(33.5)$ & $81(30.9)$ & \\
\hline $30-34$ years & $164(27.0)$ & $86(23.0)$ & $78(33.5)$ & & $157(26.5)$ & $87(26.3)$ & $70(26.7)$ & \\
\hline $35+$ years & $87(14.3)$ & $50(13.4)$ & 37 (15.9) & & $85(14.3)$ & $40(12.1)$ & $45(17.2)$ & \\
\hline \multicolumn{9}{|c|}{ Maternal highest education } \\
\hline$<$ High school & $151(26.7)$ & $115(32.3)$ & $36(17.1)$ & $<0.001$ & $136(24.2)$ & $79(25.2)$ & 57 (22.9) & 0.01 \\
\hline High school & $99(17.5)$ & $66(18.5)$ & $33(15.7)$ & & $92(16.4)$ & $64(20.4)$ & $28(11.2)$ & \\
\hline
\end{tabular}




\begin{tabular}{|c|c|c|c|c|c|c|c|c|}
\hline Trade & $236(41.7)$ & $137(38.5)$ & $99(47.1)$ & & $254(45.2)$ & $132(42.2)$ & $122(49.0)$ & \\
\hline Tertiary & $80(14.1)$ & $38(10.7)$ & $42(20.0)$ & & $80(14.2)$ & $38(12.1)$ & $42(16.9)$ & \\
\hline High family income ${ }^{b}$ & $176(31.3)$ & $100(28.9)$ & $76(35.0)$ & 0.13 & $174(32.5)$ & $97(32.0)$ & $77(33.0)$ & 0.80 \\
\hline $\begin{array}{l}\text { Father not living with } \\
\text { mother }\end{array}$ & $63(11.0)$ & $54(15.0)$ & $9(4.2)$ & $<0.001$ & $46(8.1)$ & $29(9.2)$ & $17(6.7)$ & 0.28 \\
\hline Maternal smoking & $138(22.7)$ & $107(28.7)$ & 31 (13.5) & $<0.001$ & $118(19.9)$ & $88(26.7)$ & $30(11.5)$ & $<0.001$ \\
\hline Paternal smoking & $198(34.0)$ & $148(40.5)$ & $50(22.9)$ & $<0.001$ & $178(30.8)$ & $116(36.1)$ & $62(24.2)$ & 0.002 \\
\hline Maternal alcohol use & $400(65.9)$ & $255(68.2)$ & $145(62.2)$ & 0.13 & $294(49.6)$ & $223(67.4)$ & $171(65.5)$ & 0.64 \\
\hline Maternal drug use & $56(10.1)$ & $46(13.2)$ & $10(4.9)$ & 0.002 & $33(6.0)$ & $20(6.6)$ & $13(5.3)$ & 0.53 \\
\hline Paternal drug use & $120(20.7)$ & $95(26.2)$ & $25(11.5)$ & $<0.001$ & $83(14.4)$ & $56(17.4)$ & 27 (10.6) & 0.02 \\
\hline
\end{tabular}

a. Comparison of sexually active to not sexually active group; p-values derived from chi-squared tests for categorical variables and t-tests for continuous variables.

b. $\geq$ AUS $\$ 36,000$ in $1989-1992$, the top $30 \%$ of the cohort 
Table 2. Relationship and timing of first sexual intercourse and first oral sex.

\begin{tabular}{|c|c|c|c|c|}
\hline & \multicolumn{2}{|c|}{$\begin{array}{l}\text { Female } \\
\mathrm{N}=605^{\mathrm{a}}\end{array}$} & \multicolumn{2}{|c|}{$\begin{array}{c}\text { Male } \\
\mathbf{N}=591^{a}\end{array}$} \\
\hline & \multicolumn{2}{|c|}{ First sexual intercourse } & \multicolumn{2}{|c|}{ First sexual intercourse } \\
\hline & $\begin{array}{c}\text { No } \\
n(\%)\end{array}$ & $\begin{array}{c}\text { Yes } \\
n(\%)\end{array}$ & $\begin{array}{c}\text { No } \\
n(\%)\end{array}$ & $\begin{array}{c}\text { Yes } \\
n(\%)\end{array}$ \\
\hline \multicolumn{5}{|l|}{ First oral sex } \\
\hline No & $232(38.5)$ & $16(2.7)$ & $261(44.2)$ & $11(1.9)$ \\
\hline Yes & $66(10.9)$ & $291(48.3)$ & $67(11.3)$ & $252(42.6)$ \\
\hline \multicolumn{5}{|l|}{ First oral sex } \\
\hline 3 years before first sexual intercourse & & $1(0.3)$ & & $2(0.8)$ \\
\hline 2 years before first sexual intercourse & & $11(3.8)$ & & $18(7.1)$ \\
\hline 1 year before first sexual intercourse & & $63(21.6)$ & & $72(28.6)$ \\
\hline same year as first sexual intercourse & & $188(64.6)$ & & $149(59.1)$ \\
\hline 1 year after first sexual intercourse & & $25(8.6)$ & & $11(4.4)$ \\
\hline 2 years after first sexual intercourse & & $3(1.0)$ & & $0(0)$ \\
\hline
\end{tabular}


a. Two female and two male participants had missing oral sex or sexual intercourse data. 
Table 3. Child Behavior Checklist (CBCL) behaviour problems by sexual activity status at 17 years.

\begin{tabular}{|c|c|c|c|c|c|c|}
\hline & \multicolumn{3}{|c|}{ Female, $\mathrm{N}=607$} & \multicolumn{3}{|c|}{ Male, $\mathbf{N}=\mathbf{5 9 3}$} \\
\hline & Sexually active & Not sexually & & Sexually active & Not sexually active & \\
\hline & $n(\%)$ & $n(\%)$ & $p$ & $n(\%)$ & $n(\%)$ & $p$ \\
\hline \multicolumn{7}{|c|}{ Total CBCL $\geq 60$} \\
\hline Age 2 & $27(8.8)$ & $16(8.5)$ & 0.90 & $34(12.5)$ & $22(10.3)$ & 0.45 \\
\hline Age 5 & $72(20.8)$ & $31(14.4)$ & 0.05 & $77(25.4)$ & $34(14.1)$ & 0.001 \\
\hline Age 8 & $65(18.8)$ & $31(14.3)$ & 0.17 & $66(21.4)$ & $32(13.2)$ & 0.01 \\
\hline Age 10 & $54(15.7)$ & $20(8.8)$ & 0.02 & $64(20.4)$ & $27(11.0)$ & 0.003 \\
\hline Age 14 & $47(13.4)$ & $24(10.8)$ & 0.36 & $39(13.0)$ & 19 (7.9) & 0.060 \\
\hline \multicolumn{7}{|c|}{ Externalising $\mathrm{CBCL} \geq \mathbf{6 0}$} \\
\hline Age 2 & $36(11.7)$ & $18(9.5)$ & 0.44 & $39(14.3)$ & $25(11.7)$ & 0.390 \\
\hline Age 5 & $74(21.4)$ & $22(10.2)$ & 0.001 & $67(22.1)$ & 33 (13.7) & 0.01 \\
\hline Age 8 & $63(18.2)$ & $23(10.6)$ & 0.02 & $65(21.0)$ & $32(13.2)$ & 0.02 \\
\hline
\end{tabular}


Age 10

Age 14

Internalising CBCL $\geq \mathbf{6 0}$

Age 2

Age 5

Age 8

Age 10

Age 14
49 (14.2)

53 (15.1)

$20(6.5)$

$53(15.3)$

$61(17.6)$

$57(16.5)$

$59(16.9)$
13 (5.7)

$16(7.2)$

$17(9.0)$

0.31

$25(9.2)$

$64(21.1)$

$72(23.3)$

$69(22.0)$

$24(8.0)$

$17(6.9)$

$22(9.2)$

$26(12.0)$

$29(13.4) \quad 0.18$

0.51

0.09

$\begin{array}{ll}15(7.0) & 0.39 \\ 52(21.6) & 0.90 \\ 45(18.6) & 0.18 \\ 39(15.9) & 0.07 \\ 22(9.2) & 0.62\end{array}$


Table 4. Relative rate of first sexual intercourse and first oral sex for those with behaviour problems, defined as Child Behavior Checklist (CBCL) score $\geq 60$, compared to those without behaviour problems.

\begin{tabular}{|c|c|c|c|c|c|c|c|c|}
\hline \multirow{3}{*}{ CBCL $\geq 60$} & \multicolumn{4}{|c|}{ Female, $\mathrm{N}=607$} & \multicolumn{4}{|c|}{ Male, $\mathbf{N}=593$} \\
\hline & \multirow{2}{*}{$\begin{array}{l}\text { Relative rate } \\
\text { first oral sex } \\
\text { HR }^{\mathrm{b}}(95 \% \mathrm{CI})\end{array}$} & 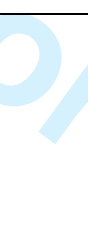 & $\begin{array}{l}\text { Relative rate firs } \\
\text { sexual } \\
\text { intercourse }^{\text {a }}\end{array}$ & & $\begin{array}{l}\text { Relative rate } \\
\text { first oral sex }\end{array}$ & & $\begin{array}{l}\text { Relative rate } \\
\text { first sexual } \\
\text { intercourse }^{\mathrm{a}}\end{array}$ & \\
\hline & & $p$ & $\mathrm{HR}^{\mathrm{b}}(95 \% \mathrm{CI})$ & $p$ & $H_{R}^{c}(95 \% C I)$ & $p$ & $\mathrm{HR}^{\mathrm{c}}(95 \% \mathrm{CI})$ & $p$ \\
\hline \multicolumn{9}{|c|}{ Externalising } \\
\hline Age 2 & $0.93(0.63-1.36)$ & 0.70 & $0.92(0.61-1.38)$ & 0.68 & $1.16(0.82-1.64)$ & 0.41 & $1.18(0.81-1.73)$ & 0.40 \\
\hline Age 5 & $1.24(0.93-1.65)$ & 0.14 & $1.21(0.89-1.64)$ & 0.23 & $1.38(1.04-1.83)$ & 0.03 & $1.39(1.02-1.90)$ & 0.04 \\
\hline Age 8 & $1.15(0.85-1.56)$ & 0.35 & $1.02(0.74-1.42)$ & 0.90 & $1.36(1.02-1.81)$ & 0.04 & $1.47(1.09-2.00)$ & 0.01 \\
\hline Age 10 & $1.40(1.00-1.98)$ & 0.05 & $1.38(0.96-1.98)$ & 0.08 & $1.55(1.14-2.11)$ & 0.005 & $1.94(1.40-2.69)$ & $<0.001$ \\
\hline Age 14 & $1.38(1.01-1.90)$ & 0.05 & $1.52(1.09-2.12)$ & 0.02 & $1.51(1.10-2.07)$ & 0.01 & $1.78(1.27-2.48)$ & 0.001 \\
\hline \multicolumn{9}{|c|}{ Internalising } \\
\hline Age 2 & $0.62(0.38-1.03)$ & 0.06 & $0.62(0.36-1.07)$ & 0.08 & $1.12(0.73-1.72)$ & 0.59 & $1.23(0.79-1.92)$ & 0.37 \\
\hline
\end{tabular}




\begin{tabular}{|c|c|c|c|c|c|c|c|c|}
\hline Age 5 & $0.95(0.69-1.32)$ & 0.77 & $0.99(0.71-1.40)$ & 0.97 & $0.97(0.72-1.29)$ & 0.82 & $1.02(0.75-1.39)$ & 0.91 \\
\hline Age 8 & $0.94(0.70-1.27)$ & 0.70 & $0.91(0.66-1.25)$ & 0.57 & $1.06(0.80-1.40)$ & 0.70 & $1.33(0.99-1.78)$ & 0.06 \\
\hline Age 10 & $0.95(0.70-1.29)$ & 0.75 & $1.02(0.73-1.40)$ & 0.93 & $1.19(0.90-1.57)$ & 0.22 & $1.39(1.03-1.87)$ & $\mathbf{0 . 0 3}$ \\
\hline Age 14 & $1.08(0.79-1.46)$ & 0.65 & $1.19(0.87-1.64)$ & 0.28 & $0.74(0.47-1.15)$ & 0.18 & $1.13(0.73-1.76)$ & 0.58 \\
\hline
\end{tabular}

a. Relative to CBCL score $<60$

b. Adjusted for maternal age and smoking, absent father at birth, and drug use by mother or father during pregnancy

c. Adjusted for maternal age and smoking during pregnancy

HR: hazard rate ratio; CI: confidence interval; CBCL: Child Behavior Checklist 
Table 5. Subset analysis: Relative risk of risky sexual and substance use behaviours at age 17, for those with externalising behaviour problems, defined as Child Behavior Checklist (CBCL) $T$-score $\geq 60$, compared to those without behaviour problems.

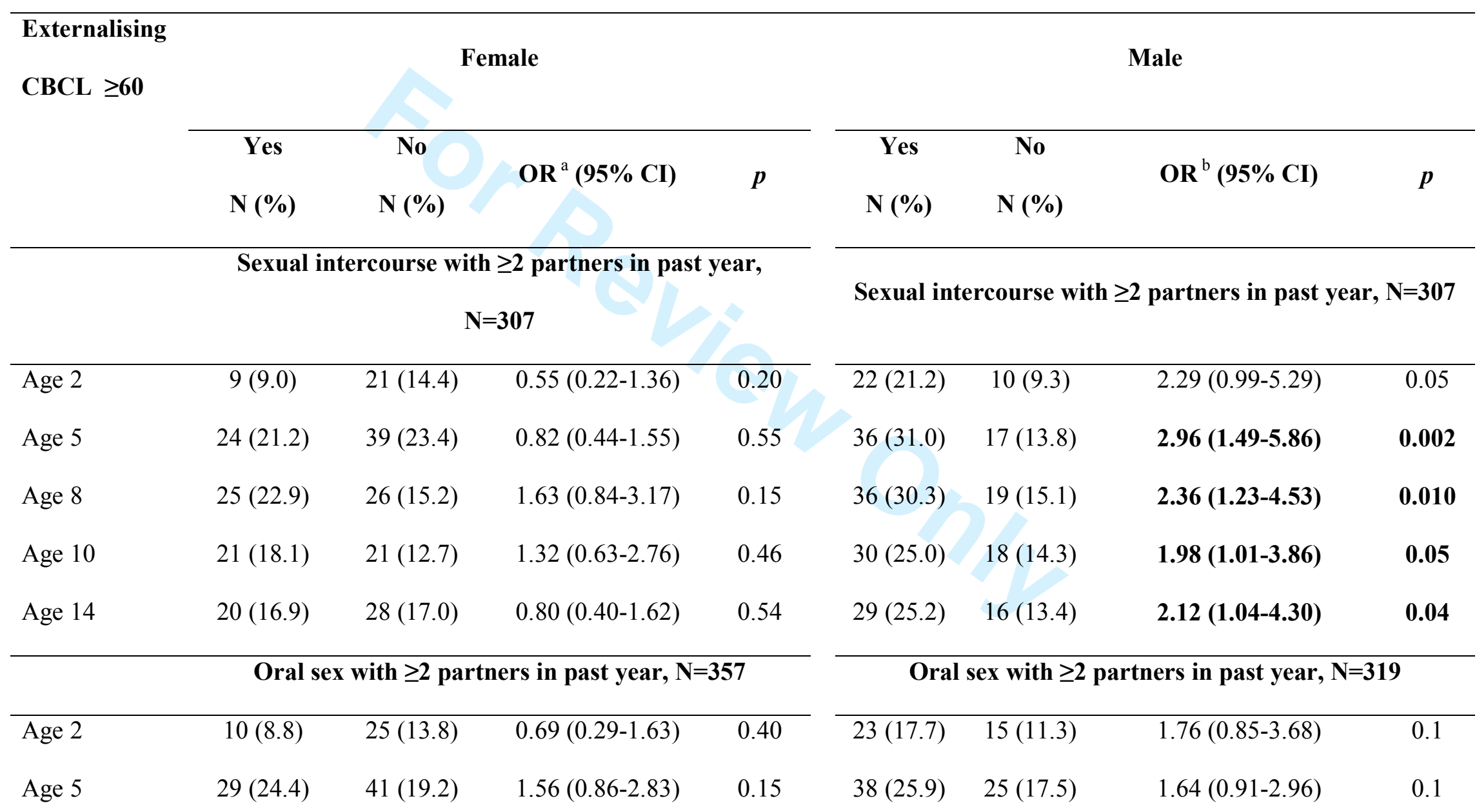




\begin{tabular}{|c|c|c|c|c|c|c|c|c|}
\hline Age 8 & $30(25.4)$ & $29(13.7)$ & $2.54(1.35-4.77)$ & 0.004 & $37(25.2)$ & $24(16.1)$ & $1.73(0.96-3.13)$ & 0.07 \\
\hline Age 10 & $21(17.2)$ & $26(12.6)$ & $1.40(0.70-2.82)$ & 0.34 & $33(22.0)$ & $18(11.9)$ & $2.19(1.13-4.23)$ & 0.02 \\
\hline Age 14 & $22(17.6)$ & $29(13.9)$ & $1.25(0.64-2.45)$ & 0.51 & $32(21.9)$ & $16(11.3)$ & $2.19(1.10-4.32)$ & 0.03 \\
\hline & \multicolumn{4}{|c|}{ Condom at last sex, $\mathbf{N}=\mathbf{3 0 7}$} & \multicolumn{4}{|c|}{ Condom at last sex, $N=263$} \\
\hline Age 2 & $18(12.9)$ & $12(11.2)$ & $0.62(0.26-1.46)$ & 0.27 & $25(15.2)$ & $7(14.3)$ & $0.64(0.24-1.68)$ & 0.36 \\
\hline Age 5 & $35(22.0)$ & $27(22.3)$ & $0.85(0.45-1.60)$ & 0.61 & $34(18.8)$ & $19(31.7)$ & $1.66(0.83-3.33)$ & 0.15 \\
\hline Age 8 & $28(17.5)$ & $22(18.3)$ & $0.91(0.47-1.77)$ & 0.78 & $38(20.2)$ & $17(28.8)$ & $1.28(0.64-2.57)$ & 0.49 \\
\hline Age 10 & $25(15.4)$ & $17(14.0)$ & $0.82(0.39-1.72)$ & 0.60 & $35(18.5)$ & $13(21.7)$ & $0.98(0.46-2.08)$ & 0.96 \\
\hline \multirow[t]{2}{*}{ Age 14} & $24(14.8)$ & $23(19.0)$ & $1.30(0.66-2.59)$ & 0.45 & $31(17.2)$ & $14(24.6)$ & $1.28(0.60-2.73)$ & 0.53 \\
\hline & \multicolumn{4}{|c|}{ Ever had sex when didn't want to, $N=307$} & \multicolumn{4}{|c|}{ Ever had sex when didn't want to, $N=263$} \\
\hline Age 2 & $14(21.9)$ & $16(8.7)$ & $1.95(0.92-4.13)$ & 0.08 & $7(23.3)$ & $25(13.6)$ & $1.90(0.67-5.42)$ & 0.23 \\
\hline Age 5 & $23(30.3)$ & $40(19.4)$ & $1.68(0.92-3.09)$ & 0.09 & $8(25.0)$ & $46(21.9)$ & $1.19(0.47-2.99)$ & 0.71 \\
\hline Age 8 & $21(27.3)$ & $30(14.6)$ & $1.91(1.04-3.53)$ & 0.04 & $8(23.5)$ & $48(22.4)$ & $1.06(0.42-2.63)$ & 0.91 \\
\hline Age 10 & $19(24.4)$ & $23(11.2)$ & $2.52(1.27-4.99)$ & 0.008 & $7(20.6)$ & $41(19.0)$ & $1.12(0.44-2.90)$ & 0.81 \\
\hline Age 14 & $19(24.1)$ & $29(14.1)$ & $2.05(1.07-3.93)$ & 0.03 & $7(22.6)$ & $38(18.4)$ & $1.42(0.54-3.78)$ & 0.48 \\
\hline
\end{tabular}




\begin{tabular}{|c|c|c|c|c|c|c|c|c|}
\hline Age 2 & $11(9.9)$ & $43(11.2)$ & $0.65(0.30-1.45)$ & 0.29 & $12(11.9)$ & $52(13.5)$ & $0.81(0.49-1.32)$ & 0.39 \\
\hline Age 5 & $31(24.6)$ & $65(14.9)$ & $1.54(0.90-2.65)$ & 0.12 & $28(26.9)$ & $72(16.4)$ & $1.80(1.26-2.57)$ & 0.001 \\
\hline Age 8 & $29(23.4)$ & $57(13.0)$ & $1.81(1.05-3.15)$ & 0.03 & $29(27.4)$ & $68(15.3)$ & $2.02(1.40-2.90)$ & $<0.001$ \\
\hline Age 10 & $21(16.9)$ & $41(9.1)$ & $1.61(0.84-3.10)$ & 0.16 & $25(22.7)$ & $45(10.0)$ & $2.23(0.15-3.33)$ & $<0.001$ \\
\hline Age 14 & $29(23.6)$ & $40(8.9)$ & $2.98(1.66-5.37)$ & $<0.001$ & $27(26.5)$ & $45(10.3)$ & $3.07(2.08-4.53)$ & $<0.001$ \\
\hline & \multicolumn{4}{|c|}{ Drunk, past 6 months, $N=607$} & \multicolumn{4}{|c|}{ Drunk, past 6 months, $N=593$} \\
\hline Age 2 & $36(10.7)$ & $15(9.9)$ & $1.41(0.75-2.64)$ & 0.29 & $45(14.4)$ & $18(10.5)$ & $1.37(0.75-2.51)$ & 0.30 \\
\hline Age 5 & $72(19.2)$ & $22(12.4)$ & $1.40(0.84-2.33)$ & 0.20 & $70(20.1)$ & $29(15.2)$ & $1.38(0.84-2.26)$ & 0.20 \\
\hline Age 8 & $58(15.3)$ & $25(14.2)$ & $1.33(0.79-2.23)$ & 0.29 & $68(19.2)$ & $28(14.7)$ & $1.36(0.82-2.24)$ & 0.23 \\
\hline Age 10 & $40(10.4)$ & $22(12.0)$ & $1.86(0.99-3.51)$ & 0.06 & $54(15.0)$ & $16(8.3)$ & $1.86(1.01-3.42)$ & 0.05 \\
\hline \multirow[t]{2}{*}{ Age 14} & $47(12.4)$ & $21(11.4)$ & $1.73(0.93-3.21)$ & 0.09 & $53(15.4)$ & $19(10.1)$ & $1.52(0.85-2.72)$ & 0.16 \\
\hline & \multicolumn{4}{|c|}{ Ever used cannabis, $N=600$} & \multicolumn{4}{|c|}{ Ever used cannabis, $N=585$} \\
\hline Age 2 & $17(10.6)$ & $34(10.4)$ & $0.67(0.33-1.37)$ & 0.27 & $22(13.7)$ & $40(12.7)$ & $0.98(0.55-1.75)$ & 0.96 \\
\hline Age 5 & $40(21.6)$ & $50(13.6)$ & $1.34(0.80-2.25)$ & 0.27 & $46(25.6)$ & $51(14.3)$ & $1.90(1.20-3.01)$ & 0.006 \\
\hline Age 8 & $30(16.6)$ & $51(13.7)$ & $1.00(0.58-1.71)$ & 0.99 & $45(24.3)$ & $50(14.0)$ & $1.81(1.14-2.87)$ & 0.01 \\
\hline Age 10 & $28(15.3)$ & $32(8.4)$ & $1.52(0.82-2.82)$ & 0.18 & $36(19.3)$ & $34(9.4)$ & $2.07(1.23-3.48)$ & 0.006 \\
\hline
\end{tabular}




\begin{tabular}{|c|c|c|c|c|c|c|c|c|}
\hline Age 14 & $343(17.8)$ & $34(9.0)$ & $1.98(1.12-3.51)$ & 0.02 & $38(21.5)$ & $34(9.6)$ & $2.28(1.36-3.84)$ & 0.002 \\
\hline & & used other & cit drugs $^{c}, N=602$ & & & ver used 0 & licit drugs ${ }^{c}, N=58$ & \\
\hline Age 2 & $11(13.6)$ & $43(10.4)$ & $1.50(0.70-3.23)$ & 0.30 & $9(13.2)$ & $55(13.2)$ & $0.90(0.41-1.97)$ & 0.79 \\
\hline Age 5 & $23(25.0)$ & $73(15.5)$ & $1.70(0.94-3.07)$ & 0.08 & $16(21.9)$ & $84(17.8)$ & $1.22(0.66-2.26)$ & 0.53 \\
\hline Age 8 & $19(20.9)$ & $67(14.2)$ & $1.67(0.91-3.07)$ & 0.10 & $21(25.9)$ & $76(16.2)$ & $1.67(0.94-2.95)$ & 0.08 \\
\hline Age 10 & $15(16.0)$ & $47(9.8)$ & $1.73(0.86-3.47)$ & 0.12 & $17(21.0)$ & $53(11.1)$ & $1.89(1.01-3.54)$ & 0.05 \\
\hline Age 14 & $24(25.3)$ & $45(9.4)$ & 3.31 (1.79-6.09) & $<0.001$ & $20(26.3)$ & $52(11.2)$ & $2.58(1.40-4.76)$ & 0.002 \\
\hline
\end{tabular}

a. Relative to CBCL score $<60$

b. Adjusted for maternal age and smoking, absent father at birth, and drug use by mother or father during pregnancy

c. Adjusted for maternal age and smoking during pregnancy

HR: hazard rate ratio; CI: confidence interval; CBCL: Child Behavior Checklist 
Table 6. Subset analyses: Relative risk of other risky sexual behaviours at age 17, for those with internalising behaviour problems, defined as Child Behavior Checklist (CBCL) score $\geq 60$, compared to those without behavior problems.

\begin{tabular}{|c|c|c|c|c|c|c|c|c|}
\hline \multirow{2}{*}{$\begin{array}{c}\text { Internalising } \\
\text { CBCL } \geq 60\end{array}$} & \multicolumn{4}{|c|}{ Female } & \multicolumn{4}{|c|}{ Male } \\
\hline & $\begin{array}{c}\text { Yes } \\
\text { N (\%) }\end{array}$ & $\begin{array}{c}\text { No } \\
\text { N (\%) }\end{array}$ & $\mathrm{OR}^{\mathrm{a}}(95 \% \mathrm{CI})$ & $\mathbf{p}$ & $\begin{array}{c}\text { Yes } \\
\text { N (\%) }\end{array}$ & $\begin{array}{c}\text { No } \\
\text { N (\%) }\end{array}$ & $\mathrm{OR}^{\mathrm{b}}(\mathbf{9 5 \%} \mathrm{CI})$ & $\mathbf{p}$ \\
\hline & \multicolumn{4}{|c|}{ Sexual intercourse with $\geq \mathbf{2}$ partners in past year, $\mathbf{N}=\mathbf{3 0 7}$} & \multicolumn{4}{|c|}{ Sexual intercourse with $\geq 2$ partners in past year, $N=263$} \\
\hline Age 2 & $5(5.0)$ & $11(7.5)$ & $0.50(0.15-1.69)$ & 0.27 & $14(13.5)$ & $8(7.5)$ & $1.70(0.67-4.34)$ & 0.27 \\
\hline Age 5 & $19(16.8)$ & $27(16.2)$ & $1.26(0.61-2.61)$ & 0.53 & $31(26.7)$ & $20(16.3)$ & $1.93(1.00-3.71)$ & 0.05 \\
\hline Age 8 & $17(15.6)$ & $33(19.3)$ & $0.71(0.36-1.43)$ & 0.34 & $38(31.9)$ & $26(20.6)$ & $1.81(0.99-3.30)$ & 0.06 \\
\hline Age 10 & $21(18.1)$ & $27(16.3)$ & $0.93(0.48-1.82)$ & 0.84 & $36(30.0)$ & $24(19.0)$ & $1.68(0.91-3.12)$ & 0.10 \\
\hline \multirow[t]{2}{*}{ Age 14} & $24(20.3)$ & $29(17.6)$ & $1.02(0.53-1.96)$ & 0.96 & $14(12.2)$ & $8(6.7)$ & $1.50(0.58-3.88)$ & 0.41 \\
\hline & \multicolumn{4}{|c|}{ Oral sex with $\geq 2$ partners in past year, $N=357$} & \multicolumn{4}{|c|}{ Oral sex with $\geq 2$ partners in past year, $N=319$} \\
\hline Age 2 & $4(3.5)$ & $14(7.7)$ & $0.32(0.09-1.19)$ & 0.09 & $18(13.8)$ & $6(4.5)$ & $3.77(1.41-10.08)$ & 0.008 \\
\hline Age 5 & $18(15.1)$ & $32(15.0)$ & $1.19(0.58-2.42)$ & 0.64 & $32(21.8)$ & $26(18.2)$ & $1.39(0.76-2.54)$ & 0.28 \\
\hline
\end{tabular}




\begin{tabular}{|c|c|c|c|c|c|c|c|c|}
\hline Age 8 & $19(16.1)$ & $39(18.5)$ & $0.86(0.46-1.64)$ & 0.65 & $38(25.9)$ & $28(18.8)$ & $1.58(0.89-2.81)$ & 0.12 \\
\hline Age 10 & $22(18.0)$ & $31(15.0)$ & $1.06(0.56-2.04)$ & 0.85 & $37(24.7)$ & $29(19.2)$ & $1.46(0.82-2.59)$ & 0.20 \\
\hline Age 14 & $27(21.6)$ & $29(13.9)$ & $1.54(0.82-2.90)$ & 0.18 & $12(8.2)$ & $9(6.3)$ & $1.43(0.56-3.65)$ & 0.46 \\
\hline & \multicolumn{4}{|c|}{ Condom at last sex, $\mathbf{N}=\mathbf{3 0 7}$} & \multicolumn{4}{|c|}{ Condom at last sex, $N=263$} \\
\hline Age 2 & $10(7.2)$ & $6(5.6)$ & $0.66(0.21-2.07)$ & 0.48 & $18(11.0)$ & $4(8.2)$ & $0.58(0.78-1.86)$ & 0.36 \\
\hline Age 5 & $25(15.7)$ & $20(16.5)$ & $1.15(0.56-2.38)$ & 0.70 & $35(19.3)$ & $16(26.7)$ & $1.36(0.66-2.77)$ & 0.40 \\
\hline Age 8 & $28(17.5)$ & $21(17.5)$ & $0.85(0.43-1.66)$ & 0.63 & $45(23.9)$ & $19(32.2)$ & $1.30(0.66-2.55)$ & 0.45 \\
\hline Age 10 & $27(16.7)$ & $21(17.4)$ & $1.10(0.57-2.13)$ & 0.79 & $41(21.7)$ & $19(31.7)$ & $1.39(0.71-2.74)$ & 0.34 \\
\hline \multirow[t]{2}{*}{ Age 14} & $30(18.5)$ & $22(18.2)$ & $0.78(0.40-1.52)$ & 0.46 & $16(8.9)$ & $6(10.5)$ & $0.77(0.27-2.22)$ & 0.63 \\
\hline & \multicolumn{4}{|c|}{ Ever had sex when didn't want to, $\mathbf{N}=\mathbf{3 0 7}$} & \multicolumn{4}{|c|}{ Ever had sex when didn't want to, $N=263$} \\
\hline Age 2 & $6(9.4)$ & $10(5.4)$ & $1.08(0.41-2.82)$ & 0.88 & $5(16.7)$ & $17(9.2)$ & $1.53(0.48-4.82)$ & 0.47 \\
\hline Age 5 & $14(18.4)$ & $31(15.5)$ & $1.02(0.50-2.04)$ & 0.97 & $7(21.9)$ & $45(21.4)$ & $1.16(0.45-3.00)$ & 0.76 \\
\hline Age 8 & $17(22.1)$ & $33(16.1)$ & $1.17(0.62-2.21)$ & 0.63 & $10(29.4)$ & $54(25.2)$ & $1.40(0.60-3.27)$ & 0.44 \\
\hline Age 10 & $16(20.5)$ & $32(15.5)$ & $1.17(0.62-2.23)$ & 0.63 & $11(32.4)$ & $49(22.7)$ & $1.77(0.77-4.09)$ & 0.18 \\
\hline Age 14 & $20(25.3)$ & $33(16.0)$ & $1.85(0.99-3.45)$ & 0.05 & $4(12.9)$ & $18(8.7)$ & $1.34(0.39-4.56)$ & 0.64 \\
\hline
\end{tabular}




\begin{tabular}{|c|c|c|c|c|c|c|c|c|}
\hline \multirow{2}{*}{$\begin{array}{l}\text { Internalizing } \\
\qquad \mathrm{CBCL} \geq \mathbf{6 0}\end{array}$} & \multicolumn{4}{|c|}{ Female } & \multicolumn{4}{|c|}{ Male } \\
\hline & $\begin{array}{c}\text { Yes } \\
\text { N (\%) }\end{array}$ & $\begin{array}{c}\text { No } \\
\text { N (\%) }\end{array}$ & $O R * *(95 \% C I)$ & $\mathbf{p}$ & $\begin{array}{c}\text { Yes } \\
\text { N (\%) }\end{array}$ & $\begin{array}{c}\text { No } \\
\text { N (\%) }\end{array}$ & OR* $(95 \% \mathrm{CI})$ & $\mathbf{p}$ \\
\hline & \multicolumn{4}{|c|}{ Smoked, past 4 weeks, $N=606$} & \multicolumn{4}{|c|}{ Smoked, past 4 weeks, $N=593$} \\
\hline Age 2 & $6(5.4)$ & $31(8.1)$ & $0.53(0.21-1.35)$ & 0.18 & $8(7.9)$ & $32(8.3)$ & $0.74(0.40-1.36)$ & 0.33 \\
\hline Age 5 & $16(12.7)$ & $63(14.4)$ & $0.70(0.36-1.36)$ & 0.29 & $23(22.1)$ & $93(21.1)$ & $0.88(0.59-1.30)$ & 0.52 \\
\hline Age 8 & $18(14.5)$ & $72(16.4)$ & $0.74(0.40-1.36)$ & 0.32 & $28(26.4)$ & $89(20.0)$ & $1.07(0.74-1.55)$ & 0.73 \\
\hline Age 10 & $20(16.1)$ & $70(15.6)$ & $0.91(0.50-1.63)$ & 0.74 & $24(21.8)$ & $84(18.8)$ & $1.05(0.72-1.53)$ & 0.82 \\
\hline \multirow[t]{2}{*}{ Age 14} & $28(22.8)$ & $57(12.7)$ & $1.86(1.06-3.27)$ & 0.03 & $8(7.8)$ & $38(8.7)$ & $1.51(0.99-2.30)$ & 0.05 \\
\hline & \multicolumn{4}{|c|}{ Drunk, past 6 months, $\mathrm{N}=607$} & \multicolumn{4}{|c|}{ Drunk, past 6 months, $N=593$} \\
\hline Age 2 & $25(7.5)$ & $10(6.6)$ & $0.69(0.33-1.46)$ & 0.33 & $24(7.7)$ & $16(9.4)$ & $0.79(0.40-1.57)$ & 0.50 \\
\hline Age 5 & $52(13.9)$ & $25(14.0)$ & $0.93(0.59-1.46)$ & 0.75 & $73(21.0)$ & $42(22.0)$ & $0.94(0.61-1.46)$ & 0.79 \\
\hline Age 8 & $56(14.8)$ & $30(17.0)$ & $0.90(0.57-1.43)$ & 0.65 & $76(21.4)$ & $40(20.9)$ & $0.96(0.61-1.50)$ & 0.85 \\
\hline Age 10 & $58(15.1)$ & $32(17.5)$ & $0.96(0.59-1.56)$ & 0.87 & $72(20.0)$ & $35(18.1)$ & $1.01(0.63-1.60)$ & 0.98 \\
\hline Age 14 & $54(14.2)$ & $29(15.8)$ & $0.58(0.30-1.12)$ & 0.11 & $24(7.0)$ & $21(11.1)$ & $0.52(0.28-0.99)$ & 0.05 \\
\hline
\end{tabular}


Ever used cannabis, $\mathbf{N}=600$

\begin{tabular}{lcccc}
\hline Age 2 & $7(4.3)$ & $29(8.9)$ & $\mathbf{0 . 2 9}(\mathbf{0 . 1 1 - 0 . 7 5})$ & $\mathbf{0 . 0 1}$ \\
Age 5 & $26(14.1)$ & $48(13.0)$ & $0.81(0.45-1.45)$ & 0.47 \\
Age 8 & $29(16.0)$ & $58(15.5)$ & $0.82(0.48-1.40)$ & 0.47 \\
Age 10 & $32(17.5)$ & $56(14.7)$ & $1.10(0.66-1.84)$ & 0.72 \\
Age 14 & $37(20.0)$ & $47(12.4)$ & $1.61(0.95-2.73)$ & 0.08 \\
\hline
\end{tabular}

\begin{tabular}{lcccc}
\hline \multicolumn{5}{c}{ Ever used other illicit drugs $\mathbf{c}, \mathbf{N}=602$} \\
\hline Age 2 & $9(11.1)$ & $28(6.7)$ & $1.41(0.60-3.28)$ & 0.43 \\
Age 5 & $14(15.2)$ & $65(13.8)$ & $0.96(0.48-1.91)$ & 0.91 \\
Age 8 & $18(19.8)$ & $72(15.3)$ & $1.25(0.68-2.32)$ & 0.47 \\
Age 10 & $17(18.1)$ & $73(15.2)$ & $1.09(0.59-2.04)$ & 0.79 \\
Age 14 & $23(24.2)$ & $62(13.0)$ & $\mathbf{2 . 1 2}(\mathbf{1 . 1 6 - 3 . 8 5})$ & $\mathbf{0 . 0 1}$
\end{tabular}

OR: odds ratio; CI: confidence interval; CBCL: Child Behavior Checklist
a. Adjusted for maternal age and smoking, absent biological father, and drug use by mother or father during pregnancy
b. Adjusted for maternal age and smoking during pregnancy
c. Illicit drugs: amphetamines and party drugs (ecstasy, acid, etc.)

Ever used cannabis, $\mathrm{N}=\mathbf{5 8 5}$

\begin{tabular}{|c|c|c|c|}
\hline $15(9.3)$ & $25(7.9)$ & $1.11(0.56-2.21)$ & 0.77 \\
\hline $39(21.7)$ & $75(21.1)$ & $1.00(0.64-1.55)$ & 0.99 \\
\hline $52(28.1)$ & $62(17.4)$ & $1.70(1.10-2.62)$ & 0.02 \\
\hline $42(22.5)$ & $64(17.7)$ & $1.21(0.78-1.90)$ & 0.40 \\
\hline $12(6.8)$ & $34(9.6)$ & $0.60(0.30-1.21)$ & 0.16 \\
\hline \multicolumn{4}{|c|}{ Ever used other illicit drugs $^{c}, \mathbf{N}=586$} \\
\hline $5(7.4)$ & $35(8.4)$ & $0.78(0.29-2.11)$ & 0.63 \\
\hline $12(16.4)$ & $104(22.1)$ & $0.66(0.34-1.29)$ & 0.23 \\
\hline $23(28.4)$ & $94(20.0)$ & $1.42(0.82-2.46)$ & 0.21 \\
\hline $18(22.2)$ & $90(18.9)$ & $1.08(0.60-1.95)$ & 0.79 \\
\hline $4(5.3)$ & $42(9.1)$ & $0.50(0.17-1.45)$ & 0.20 \\
\hline
\end{tabular}

